\title{
Synthesis of nanocrystalline mixed metal fluorides in nonaqueous medium
}

\author{
NEETU TYAGI, EPSITA GHANTI, NIKESH GUPTA, N P LALLA ${ }^{\dagger}$ and \\ RAJAMANI NAGARAJAN* \\ Department of Chemistry, University of Delhi, Delhi 110 007, India \\ ${ }^{\dagger}$ Inter University Consortium for DAE Facilities, University Campus, Indore 452 017, India
}

MS received 1 July 2008

\begin{abstract}
Synthesis of mixed metal fluorides of the general formula, $\mathrm{KMF}_{3}(\mathrm{M}=\mathrm{Mg}, \mathrm{Mn}, \mathrm{Co}, \mathrm{Ni}, \mathrm{Cu}$ and $\mathrm{Zn}$ ), possessing perovskite structure was investigated in non-aqueous medium. The fluorides were characterized by powder X-ray diffraction, FT-IR spectroscopy, thermal analysis, SEM and TEM. Monophasic cubic phases were obtained for the central metal ions such as $\mathrm{Mg}, \mathrm{Mn}, \mathrm{Co}, \mathrm{Ni}$, and $\mathrm{Zn}$ and a tetragonally distorted phase was observed for $\mathrm{Cu}$. The usage of non-aqueous medium is advantageous for the bulk synthesis of these fluorides, since it eliminated the generation and handling of the hazardous HF that has usually been encountered during aqueous preparations. The average crystallite size of the fluorides obtained by this approach was estimated to be in the range of 9-30 nm. SEM micrographs of $\mathrm{KZnF}_{3}$ showed cubic morphology of perovskite phases. TEM studies on $\mathrm{KCuF}_{3}$ confirmed the presence of tetragonal distortion. The fluoride content was determined by titrimetry and found to be nearly stoichiometric. Some of these fluorides were found to be thermally stable up to $225^{\circ} \mathrm{C}$ in air. These fluorides were employed as fluorinating agents in organic fluorination reactions, thereby suggesting their possible utilization for selective fluorination of aliphatic and aromatic hydrofluorocarbons (HFCs) that are industrially relevant.
\end{abstract}

Keywords. Fluorides; perovskites; nanomaterials; soft synthesis; X-ray diffraction; non-stoichiometry.

\section{Introduction}

Materials possessing perovskite structure have received enormous attention over the past two decades because of their interesting properties such as high-temperature superconductivity and colossal magnetoresistivity (Rao and Raveau 1995). With the advent of nanoscience and nanotechnology much effort has been devoted to the synthesis of inorganic materials with specific morphologies possessing unique optical and electronic properties (Rao et al 2007). There has been an increased interest in the study of simple ternary fluorides with perovskite structures (e.g. $\mathrm{KMgF}_{3}, \mathrm{KMnF}_{3}, \mathrm{KNiF}_{3}, \mathrm{KZnF}_{3}$ ) because of their interesting structural and physical properties, such as magnetism, photoluminescence and piezoelectricity (Hirakawa et al 1960; Knox 1961; Suemune and Ikawa 1964; Holloway and Kestigian 1966; Svensson et al 1969; Gesi et al 1972; Rose et al 1976; Takeuchi et al 1979; Yamaguchi et al 1999). The synthesis and characterization of fluorometallates which are iso-electronic and iso-structural with their oxide counterparts is the subject of the present investigation. Traditionally complex fluorides are prepared by solid state reaction at high tempera-

\footnotetext{
*Author for correspondence (rnagarajan $@$ chemistry.du.ac.in)
}

ture $\left(>400^{\circ} \mathrm{C}\right)$ and high pressure or by high pressure (>100 MPa) hydrothermal technique (Demiamets 1990). A milder hydrothermal synthesis of the complex fluorides at $120-240^{\circ} \mathrm{C}$ has also been reported (Zhao et al 1996 , 1997; Xun et al 1997, 1998). The major difficulties that are encountered in the synthesis of fluoride perovskites are the choice of the container, the evolution of hydrofluoric acid $(\mathrm{HF})$ and the corrosive nature of the fluorine gas which also may lead to the non-stoichiometry of the products. In the case of $\mathrm{KCuF}_{3}$ prepared from aqueous solutions, replacement of one fluoride ion by one hydroxyl ion resulting in a composition of $\mathrm{KCu}(\mathrm{OH}) \mathrm{F}_{2}$ has been observed (Machin et al 1963; Li et al 2000). The oxygen content in the complex fluorides synthesized by solid state reaction was higher than that of the corresponding complex fluorides synthesized by hydrothermal technique (Haendler et al 1958). The earliest work on the synthesis of these fluorometallates in non-aqueous medium was carried out by Crocket and Haendler (1960), for the synthesis of $\mathrm{NH}_{4} \mathrm{MF}_{3}(\mathrm{M}=\mathrm{Cd}, \mathrm{Co}, \mathrm{Cu}, \mathrm{Mn}, \mathrm{Zn}, \mathrm{Mg}, \mathrm{Fe})$ in methanol in the year 1958. They extended the same approach for the preparation of $\mathrm{KMF}_{3}$ and $\mathrm{RbMF}_{3}$ $(\mathrm{M}=\mathrm{Cd}, \mathrm{Co}, \mathrm{Cu}, \mathrm{Mn}, \mathrm{Zn}, \mathrm{Fe})$. Recently, $\mathrm{KMgF}_{3}$ and $\mathrm{KZnF}_{3}$ were prepared in ethylene glycol at $150-180^{\circ} \mathrm{C}$ using an autoclave (Hua et al 2002). Also $\mathrm{KNiF}_{3}$ has been prepared solvothermally at $110^{\circ} \mathrm{C}$ using ethanol (Zhang et 
al 2005). Very recently, $\mathrm{KZnF}_{3}$ and $\mathrm{KCdF}_{3}$ crystals were obtained in methanol employing mild solvothermal synthesis (Huang et al 2005). While the non-aqueous approach provides an easy means for the synthesis, the solvothermal method required the use of autoclaves. Although many different synthetic routes have been described in the literature for the preparation of these fluorides, there has not been any comprehensive study describing the nature of the products from the nonaqueous medium, their thermal stability and possible applications. During the preparation of our paper, we came across a publication describing microwave assisted metathesis synthesis of these fluorides (Parhi and Manivannan 2008). However, the hazardous fluorine gas evolution may occur in these kinds of reactions. In the present study, we have prepared fluorometallates possessing perovskite structure through soft chemistry or a green synthetic approach by the use of non-aqueous medium which eliminates the use of harsh conditions such as high temperatures and high pressures that were generally employed to obtain these fluorides. Also the preparations through non-aqueous medium resulted in final products with improved stoichiometry. These fluorides were characterized by the powder X-ray diffraction, FTIR spectroscopy, transmission electron microscopy and thermal analysis. For the first time, we have also demonstrated the application of these fluorides in organic fluorination reactions.

\section{Experimental}

Typically divalent metal chlorides were first dissolved in absolute methanol (HPLC Grade) and added to potassium fluoride in absolute methanol. The molar ratio of potassium fluoride to metal chlorides was kept $3: 1$ in all the preparations. The solid product obtained was filtered, washed with ethanol followed by acetone and air dried. Perkin-Elmer FT-IR spectrometer model 2000 was employed to obtain the absorption spectra of the powder samples using $\mathrm{KBr}$ as the dispersal medium. The powder $\mathrm{X}$-ray diffraction patterns were recorded using Bruker D8 Advance Diffractometer employing $\mathrm{Cu} \mathrm{K} \alpha$ radiation. The fluoride content of the samples was estimated by titrating against the standardized thorium nitrate solution using sodium alizarin sulphonate as indicator (Cumming and Kay 1956). A Tecnai 20 G2 (FEI make) transmission electron microscope at $200 \mathrm{kV}$ was used to carry out TEM studies. Thermal analysis of the samples was carried out using Shimadzu DTG-60 instrument. The ${ }^{19} \mathrm{~F}$ NMR spectrum was recorded using Bruker Toxispin (300 MHz) spectrometer.

\section{Results and discussion}

We prepared $\mathrm{KMF}_{3}(\mathrm{M}=\mathrm{Mg}, \mathrm{Mn}, \mathrm{Co}, \mathrm{Ni}, \mathrm{Cu}$ and $\mathrm{Zn})$ in aqueous medium following the procedure of Langley et al (1984). However, from the observation of etching of glass beakers used for the synthesis, we concluded that in the aqueous medium one cannot avoid the generation of hydrofluoric acid. The generation of HF might be one of the main reasons for the non-stoichiometry observed in the total fluoride content and also for the presence of hydroxyl groups in the final products as observed in earlier reports (Haendler et al 1958; Crocket and Haendler 1960). We have chosen non-aqueous medium for the synthesis of these ternary fluorides mainly for two reasons viz. safety and to minimize the fluoride content loss during synthesis. In figure 1 , we show the powder X-ray diffraction patterns of $\mathrm{KMF}_{3}(\mathrm{M}=\mathrm{Mn}, \mathrm{Co}$ and $\mathrm{Mg})$ prepared via non-aqueous medium. While $\mathrm{KMgF}_{3}$ and

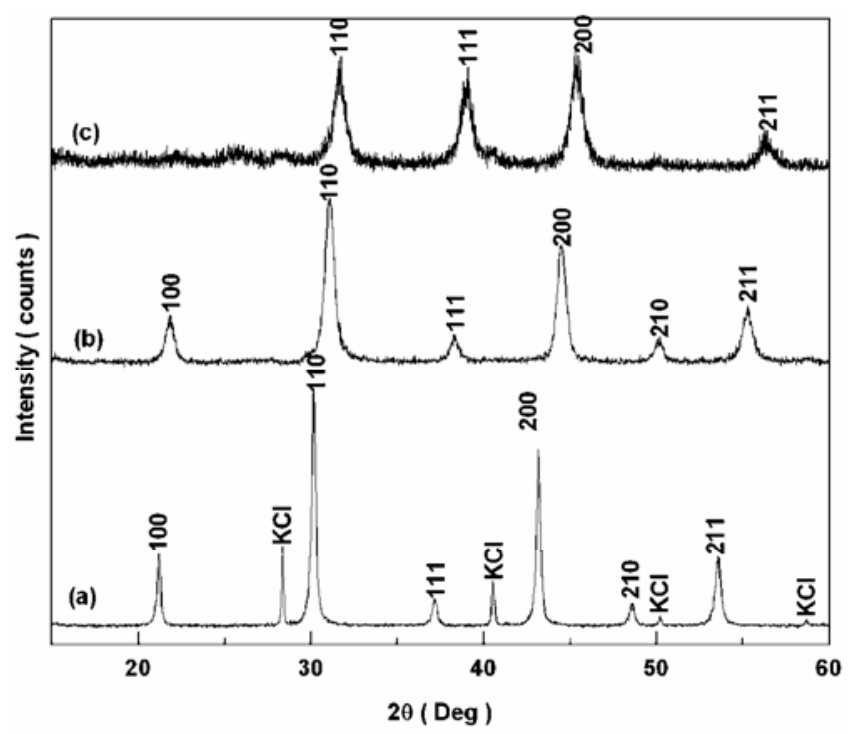

Figure 1. Powder X-ray diffraction patterns of (a) $\mathrm{KMnF}_{3}$, (b) $\mathrm{KCoF}_{3}$ and (c) $\mathrm{KMgF}_{3}$.

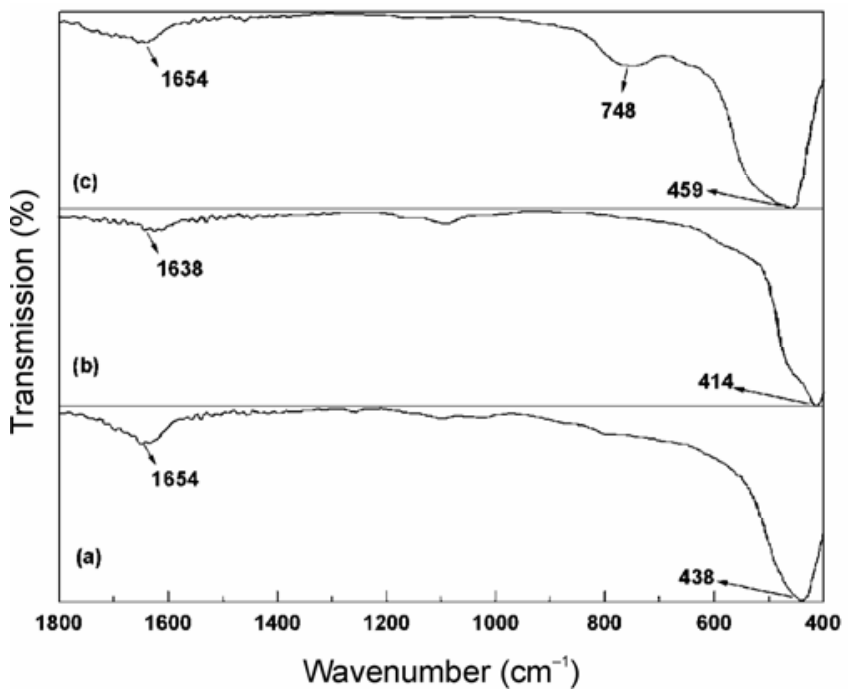

Figure 2. FTIR spectra of (a) $\mathrm{KMnF}_{3}$, (b) $\mathrm{KCoF}_{3}$ and (c) $\mathrm{KMgF}_{3}$. 
$\mathrm{KMnF}_{3}$ were white coloured fine powders, $\mathrm{KCoF}_{3}$ was bright pink in colour. We have observed the formation of $\mathrm{KCl}$ in our preparations along with the fluoride as reported in the solvothermal approach by Zhang et al (2005). The cubic lattice constants of our preparations were $4 \cdot 186(2), 4 \cdot 063(5)$ and $3.997(1) \AA$ for $\mathrm{KMnF}_{3}$, $\mathrm{KCoF}_{3}$ and $\mathrm{KMgF}_{3}$, respectively and they agreed well with the reported values (JCPDS Cards 821334; 712442; 181033). We calculated the average crystallite size from the powder X-ray diffraction patterns of $\mathrm{KMnF}_{3}, \mathrm{KCoF}_{3}$ and $\mathrm{KMgF}_{3}$ using Scherrer's formula (Cullity 1978) to be 28,12 and $17 \mathrm{~nm}$, respectively. In the literature, $\mathrm{KMnF}_{3}$ and $\mathrm{KCoF}_{3}$ prepared by an aqueous approach contained oxy, hydroxyl groups or the hydrates (Wanklyn et al 1979). We examined our preparations by FT-IR spectroscopy for the presence of oxy, hydroxyl or hydrates. The FT-IR spectra of $\mathrm{KMnF}_{3}, \mathrm{KCoF}_{3}$ and $\mathrm{KMgF}_{3}$ are shown in figure 2. We observed shallow bands in 3430$3450 \mathrm{~cm}^{-1}$ region and around $1645 \mathrm{~cm}^{-1}$ in all the three cases corresponding to the antisymmetric and symmetric $\mathrm{OH}$ stretching and $\mathrm{HOH}$ bending modes of lattice water (Nakamoto 1978). In addition to these bands, we observed a strong band between 420 and $430 \mathrm{~cm}^{-1}$ and a shoulder at $720 \mathrm{~cm}^{-1}$ that could be assigned to $\mathrm{M}-\mathrm{F}$ stretching $(\mathrm{M}=\mathrm{Mn}, \mathrm{Co}$ and $\mathrm{Mg}$ ) and phonon modes (Nakagawa et al 1967; Young and Perry 1967). The total fluoride content by titration indicated a perfectly stoichiometric compound. This synthetic approach for making bulk fluorides of $\mathrm{Mg}, \mathrm{Mn}$ and Co may facilitate the study of their luminescent properties by doping of suitable activators (Furetta et al 2001).

We prepared $\mathrm{KNiF}_{3}$ and $\mathrm{KZnF}_{3}$ possessing cubic perovskite structure in non-aqueous medium. The SEM micrograph of $\mathrm{KZnF}_{3}$ confirmed the cubic morphology of the powders (figure 3). We focused more on the preparation of $\mathrm{KCuF}_{3}$ using non-aqueous medium for a variety of reasons. Firstly, $\mathrm{Cu}^{2+}$ being a Jahn-Teller ion, $\mathrm{KCuF}_{3}$ exists in two poly types with varying stacking disorder (Hutchings et al 1969; Towler and Dovesi 1995). Secondly, the presence of hydroxyl groups in place of fluoride ions seriously affects the magnetic properties of bulk $\mathrm{KCuF}_{3}$ (Haendler et al 1958). We obtained tetragonal $\mathrm{KCuF}_{3}$ by reacting methanol solutions of $\mathrm{CuCl}_{2} \cdot 2 \mathrm{H}_{2} \mathrm{O}$ or $\mathrm{CuBr}_{2} \cdot 2 \mathrm{H}_{2} \mathrm{O}$ with $\mathrm{KF}$ at room temperature. In figure 4, we show the powder $\mathrm{X}$-ray diffraction patterns of $\mathrm{KCuF}_{3}$ prepared from $\mathrm{CuCl}_{2} \cdot 2 \mathrm{H}_{2} \mathrm{O}$ as well as $\mathrm{CuBr}_{2} \cdot 2 \mathrm{H}_{2} \mathrm{O}$. It is noteworthy that $\mathrm{KBr}$ formed when cupric bromide is used as the copper source, dissolves in methanol with time thereby eliminating the necessity of water washing. In the case of $\mathrm{KCuF}_{3}$, the crystallite size was in the range $9-16 \mathrm{~nm}$. The splitting of highly intense (200) and (112) $\mathrm{hkl}$ reflections observed in the powder $\mathrm{X}$-ray diffraction pattern of $\mathrm{KCuF}_{3}$ prepared from $\mathrm{CuCl}_{2} \cdot 2 \mathrm{H}_{2} \mathrm{O}$ was absent when $\mathrm{CuBr}_{2} \cdot 2 \mathrm{H}_{2} \mathrm{O}$ was used as the starting material. The tetragonal lattice parameters for $\mathrm{KCuF}_{3}$ were $a=4.138 \AA, c=3.945 \AA$ (prepared from
$\mathrm{CuCl}_{2} \cdot 2 \mathrm{H}_{2} \mathrm{O}$ ) and $a=4 \cdot 120 \AA, c=3.964 \AA$ (prepared from $\mathrm{CuBr}_{2} \cdot 2 \mathrm{H}_{2} \mathrm{O}$ ) matched well with the values from literature (JCPDS Cards 730233; 730232). We could not prepare $\mathrm{KCuF}_{3}$ if $\mathrm{CuI}$ is used as the starting material. The fluoride content estimation confirmed that the compounds were stoichiometric. These studies suggest that highly reactive organometallic species containing halides might be formed in methanol at room temperature as suggested by earlier theoretical results and experimental studies (Bradley et al 1957; Karim et al 1997; Faralli et al 2007). We strongly believe that this synthetic method can be considered as green as it is a safer chemistry which is energy efficient requiring no harsh conditions. It is important to note that higher members in this series such

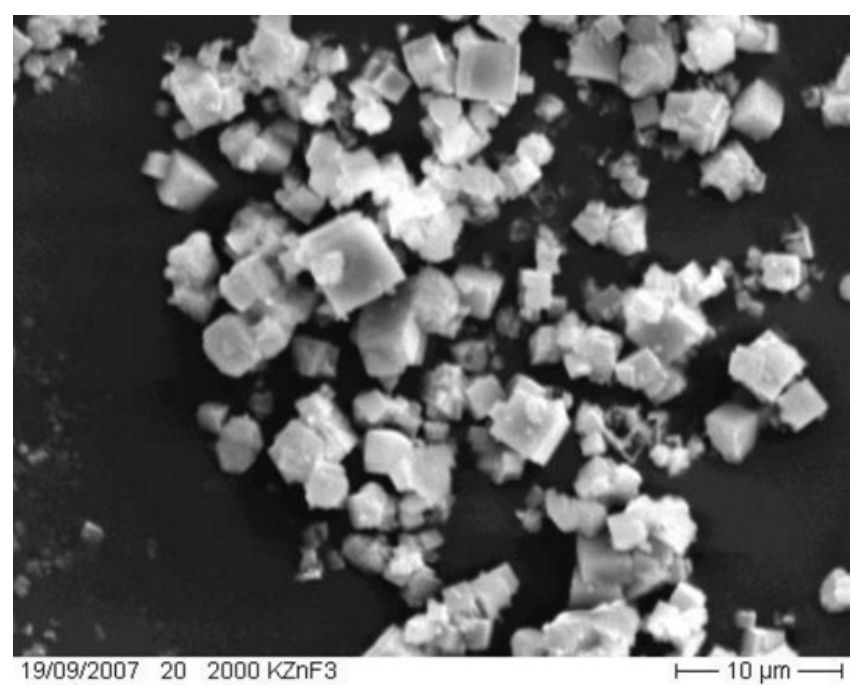

Figure 3. Scanning electron microscopy image of $\mathrm{KZnF}_{3}$.

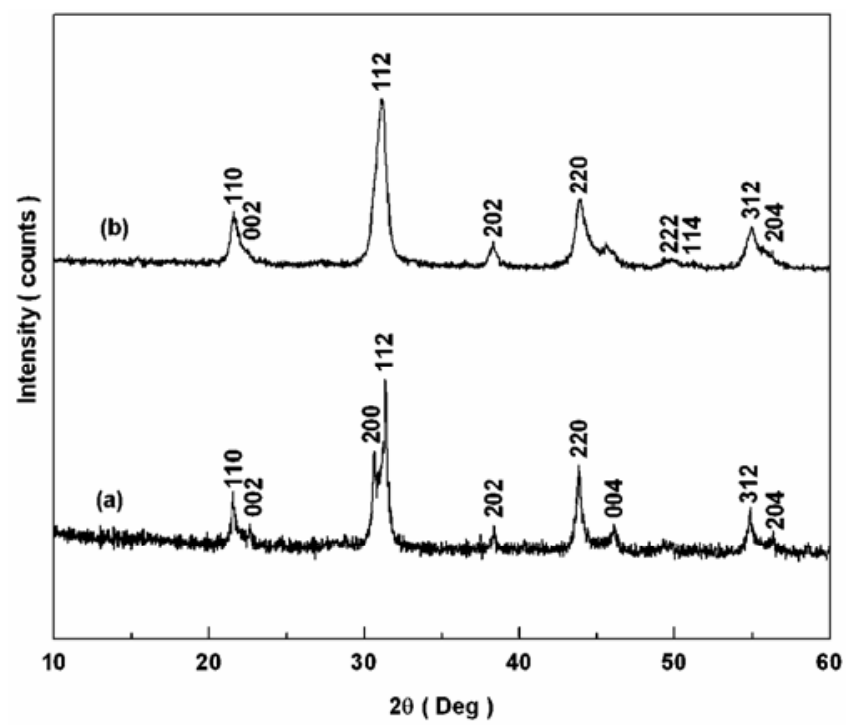

Figure 4. Powder $\mathrm{X}$-ray diffraction pattern of $\mathrm{KCuF}_{3}$ prepared via nonaqueous medium using (a) $\mathrm{CuCl}_{2} \cdot 2 \mathrm{H}_{2} \mathrm{O}$ and (b) $\mathrm{CuBr}_{2} \cdot 2 \mathrm{H}_{2} \mathrm{O}$. 
as $\mathrm{K}_{2} \mathrm{CuF}_{4}, \mathrm{~K}_{2} \mathrm{NiF}_{4}$ could not be prepared by this method. In figures 5(a) and (b) we show the electron diffraction and TEM images of $\mathrm{KCuF}_{3}$ confirming the tetragonal unit cell of nano crystallites.

We performed thermogravimetric studies in air of $\mathrm{KCuF}_{3}$ to investigate the thermal stability and nature of decomposition product. From the thermogram shown in figure 6, it appeared that there was no appreciable mass loss till $225^{\circ} \mathrm{C}$. After this temperature the mass loss took place gradually and appreciably till $900^{\circ} \mathrm{C}$. The total mass loss of $14 \%$ suggested that the product obtained at $900^{\circ} \mathrm{C}$ might correspond to $\mathrm{KCuOF}$; such a compound has not yet been reported in the literature. We could not verify the structure and composition of the left over product at $900^{\circ} \mathrm{C}$ because of the experimental difficulties associated with heating $\mathrm{KCuF}_{3}$ in macroscale quantities. However, under highly oxidizing conditions such as the $\mathrm{LiNO}_{3}-\mathrm{KNO}_{3}$ eutectic mixture flux, we got the respective divalent metal oxides.

It is well known that alkali metal fluorides have wide applications in the organo fluorine chemistry both as a
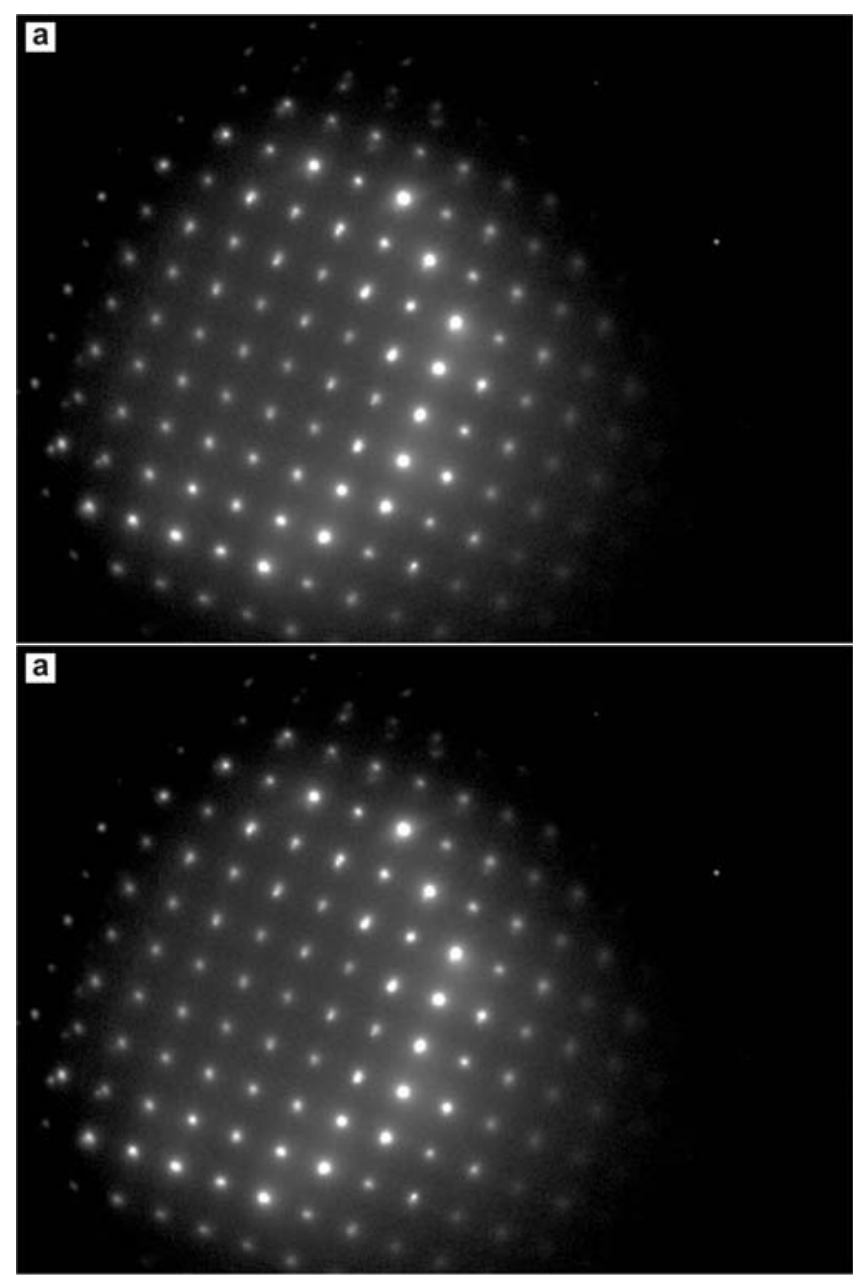

Figure 5. a. Electron diffraction pattern of $\mathrm{KCuF}_{3}$ and $\mathbf{b}$. transmission electron microscopy image of $\mathrm{KCuF}_{3}$. fluorinating agent as well as a catalyst in various reactions (Yakobson and Akhmetova 1983). We were interested to examine whether the ternary perovskite structure type fluorides could act as fluorinating agent in an organic reaction. Typically, $o$-chloronitrobenzene $(3 \cdot 15 \mathrm{~g}$, $1 \mathrm{~mol}), \mathrm{KNiF}_{3}(1.74 \mathrm{~g}, 1.5 \mathrm{~mol})$, DMSO $(8.5 \mathrm{ml}, 6 \mathrm{~mol})$, benzyltriethylammonium chloride $(0.455 \mathrm{~g}, \quad 0.1 \mathrm{~mol})$ were refluxed at $170^{\circ} \mathrm{C}$ for $\sim 3 \mathrm{~h}$. The product was filtered and the filtrate was treated with $\mathrm{CHCl}_{3}-\mathrm{H}_{2} \mathrm{O}$ system several times to extract the fluorinated product in the organic layer. The extracted layer was evaporated under reduced pressure to obtain the final compound. The fluorinated product showed a singlet at $\delta=118 \mathrm{ppm}$ in the ${ }^{19} \mathrm{~F}$ NMR spectrum. These ternary fluorides were found to be stable up to $225^{\circ} \mathrm{C}$ in the solid state, but liberate fluorine at $170^{\circ} \mathrm{C}$ under refluxing in DMSO to yield fluorinated organic product. This observation suggested the use of ternary fluorides for the manufacture of aliphatic and aromatic hydrofluorocarbons (HCFs) where direct and selective conversion of $\mathrm{C}-\mathrm{H}$ bond to a $\mathrm{C}-\mathrm{F}$ bond is desirable (Subramanian and Calvarese 2006).

\section{Conclusions}

In conclusion, nearly stoichiometric fluorides of the general formula, $\mathrm{KMF}_{3}(\mathrm{M}=\mathrm{Mg}, \mathrm{Mn}, \mathrm{Co}, \mathrm{Ni}, \mathrm{Cu}$ and $\mathrm{Zn}$ ), possessing perovskite structure were prepared in nonaqueous medium. This reaction eliminates the generation of harmful hydrofluoric acid and is driven by salt $(\mathrm{KCl})$ formation which is harmless. The average crystallite size of the fluorides obtained by this method was in the range $9-30 \mathrm{~nm}$ and was thermally stable up to $225^{\circ} \mathrm{C}$ in air. For the first time, these fluorides have been

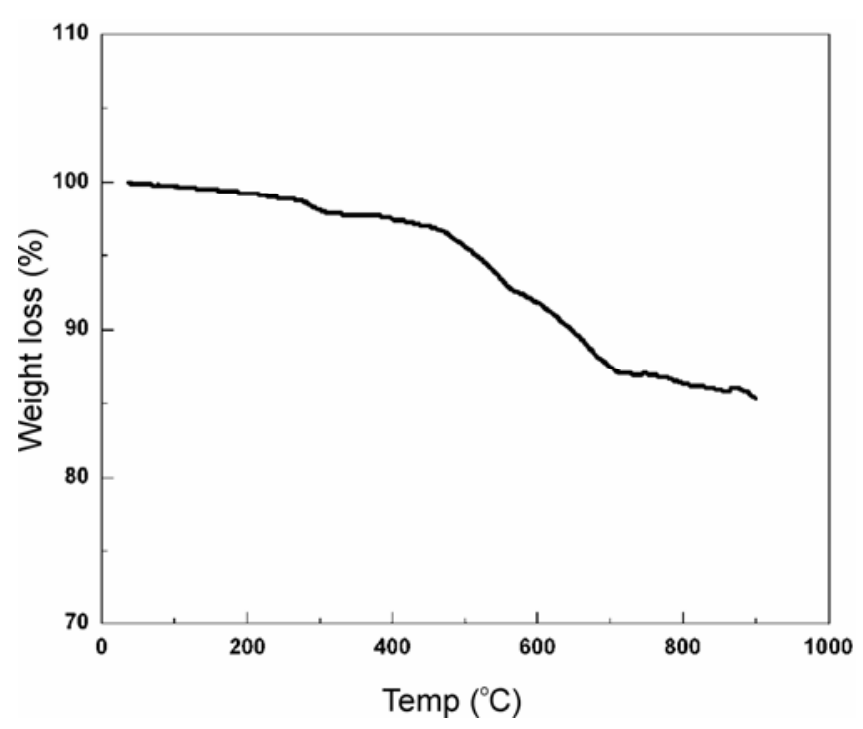

Figure 6. Plot of percentage mass lost vs temperature of $\mathrm{KCuF}_{3}$ in air. 
demonstrated to be used as fluorinating agents in organic fluorination reactions.

\section{Acknowledgements}

The authors record their sincere and grateful thanks to the University of Delhi and the Department of Science and Technology, Government of India, for financial support for carrying out this work. Our sincere thanks to Prof. A K Ganguli and Prof. A Ramanan, Indian Institute of Technology, Delhi, and the UGC-DAE Consortium, Indore, for the use of their powder X-ray diffraction facility. The authors also wish to acknowledge useful discussions with Dr S Uma, Department of Chemistry, University of Delhi, Delhi.

\section{References}

Bradley D C, Caldwell E V and Wardlaw W 1957 J. Chem. Soc. 3039

Crocket D S and Haendler HM 1960 J. Am. Chem. Soc. 82 4158

Cullity B D 1978 Elements of X-ray diffraction (AddisonWesley) 2nd edn

Cumming and Kay 1956 Quantitative chemical analysis (Edinburgh: Oliver and Boyd Ltd.) 11th edn

Demiamets L N 1990 Prog. Cryst. Growth Charact. 21299

Faralli C, Pagliai M, Cardini G and Schettino V 2007 Theor. Chem. Acc. 118417

Furetta C, Santopietro F, Sanipoli C and Kitis G 2001 Appl. Rad. Iso. 55533

Gesi K, Axe J D and Shirane G 1972 Phys. Rev. B5 1933

Haendler H M, Johnson F A and Crocket D S $1958 \mathrm{~J}$. Am. Chem. Soc. 802662

Hirakawa K, Hirakawa K and Hasimoto T 1960 J. Phys. Soc. Jap. $\mathbf{1 5} 2063$

Holloway W W and Kestigian M 1966 J. Chem. Phys. 45 639

Hua R, Jia Z, Xie D and Shi C 2002 Mater. Res. Bull. 37 1189

Huang B, Hong J M, Chen X T, Yu Z and You X Z 2005 Mater. Lett. 59430
Hutchings M T, Samuelsen E J and Shirane G 1969 Phys. Rev. 188919

Karim A, Labban S and Marcus Y 1997 J. Solution Chem. 261

Knox K 1961 Acta Crystallogr. 14583

Langley R H, Schmitz C K and Langley M B 1984 J. Chem. Educ. 61643

Li H, Jia Z, Feng S and Shi C 2000 Chem. J. Chinese U. 12 1805

Machin D J, Martin R L and Nyholm R S 1963 J. Chem. Soc. 1481490

Nakagawa I, Tsuchida A and Shimanouchi T 1967 J. Chem. Phys. 47982

Nakamoto K 1978 Infrared and Raman spectra of inorganic and coordination compounds (New York: Wiley Interscience) 3rd edn

Parhi P and Manivannan V 2008 Mater. Lett. 623468

Rao C N R and Raveau B (eds) 1995 Transition metal oxides (New York: VCH Publishers)

Rao C N R, Vivekchand S R C, Biswas K and Govindaraj A 2007 Dalton Trans. 3728

Rose R H, Rhoads JE and Halliburton L E 1976 Phys. Rev. B14 3583

Subramanian M A and Calvarese T G 2006 Adv. Fluor. Sci. 2 203

Suemune Y and Ikawa H 1964 J. Phys. Soc. Jap. 191686

Svensson E S, Buyers W J L, Holden T M, Cowley R A and Stevenson R W H 1969 Canadian J. Phys. 471983

Takeuchi H, Horai K and Arakawa M 1979 J. Phys. Soc. Jap. 4618

Towler M D and Dovesi R 1995 Phys. Rev. B52 10150

Wanklyn B M, Wondre F R, Maqsood A and Yanagisawa K J 1979 J. Mater. Sci. 141447

Xun X, Feng S, Wang J and Xu R 1997 Chem. Mater. 92966

Xun X, Feng S and Xu R 1998 Mater. Res. Bull. 33369

Yakobson G G and Akhmetova N E 1983 Synthesis 169

Yamaguchi H, Katsumata K, Hagiwara M, Tokunaga M, Liu H L, Zibold A, Tanner D B and Wang Y J 1999 Phys. Rev. B59 6021

Young E F and Perry C H 1967 J. Appl. Phys. 384624

Zhang M, Wang Z, Mo M, Chen X, Zhang R and Yu W 2005 Mater. Chem. Phys. 89373

Zhao C, Feng S, Chao Z, Shi C, Xu R and Ni J 1996 Chem. Commun. 141641

Zhao C, Feng S, Xu R, Shi C and Ni J 1997 Chem. Commun. 945 